\title{
Behavioral Science-Informed Technology Interventions for Change in Residential Energy Consumption
}

\begin{tabular}{|c|c|}
\hline Matthew Crowley & Kevin Mori \\
\hline ChangeLabs & ChangeLabs \\
\hline School of Engineering - Design & School of Engineering - Design \\
\hline Stanford University & Stanford University \\
\hline Stanford, CA 94305 USA & Stanford, CA 94305 USA \\
\hline matt89@stanford.edu & kdolphin@stanford.edu \\
\hline Aurélia Heitz & Banny Banerjee \\
\hline ChangeLabs & Stanford, Design Program, \\
\hline School of Engineering - Design & Director, ChangeLabs \\
\hline Stanford University & Stanford University \\
\hline Stanford, CA 94305 USA & Stanford, CA 94305 USA \\
\hline aheitz@stanford.edu & banny@stanford.edu \\
\hline \multicolumn{2}{|l|}{ Annika Matta } \\
\hline \multicolumn{2}{|l|}{ ChangeLabs } \\
\hline \multicolumn{2}{|l|}{ School of Engineering - Design } \\
\hline \multicolumn{2}{|l|}{ Stanford University } \\
\hline Stanford, CA 94305 USA & \\
\hline
\end{tabular}

\section{changeLabs.}

Copyright is held by the author/owner(s).

CHI 2011, May 7-12, 2011, Vancouver, BC, Canada.

ACM 978-1-4503-0268-5/11/05.

\section{Abstract}

Behavior change represents an important new approach to addressing the energy crisis. Utility companies and private companies are deploying sensor-based power meters and related residential electricity monitoring technologies with the view that monitoring energy use will eventually result in a reduction in energy consumption. The success of these technologies depends largely on homeowners responding to the data with appropriate changes in their consumption behavior. Most energy feedback interfaces, however, have not been designed through a human-centered process and display data in ways that are unlikely to change behavior. Our proposal is to design interactive interfaces that combine a deeply human-centered process with insights from behavioral economics to reduce residential energy consumption. This paper describes our current research to develop and evaluate interactive interfaces based on three motivational categories: cognitive, social, and affective.

\section{Keywords}

User interface design, home, sustainability, usability testing and evaluation 


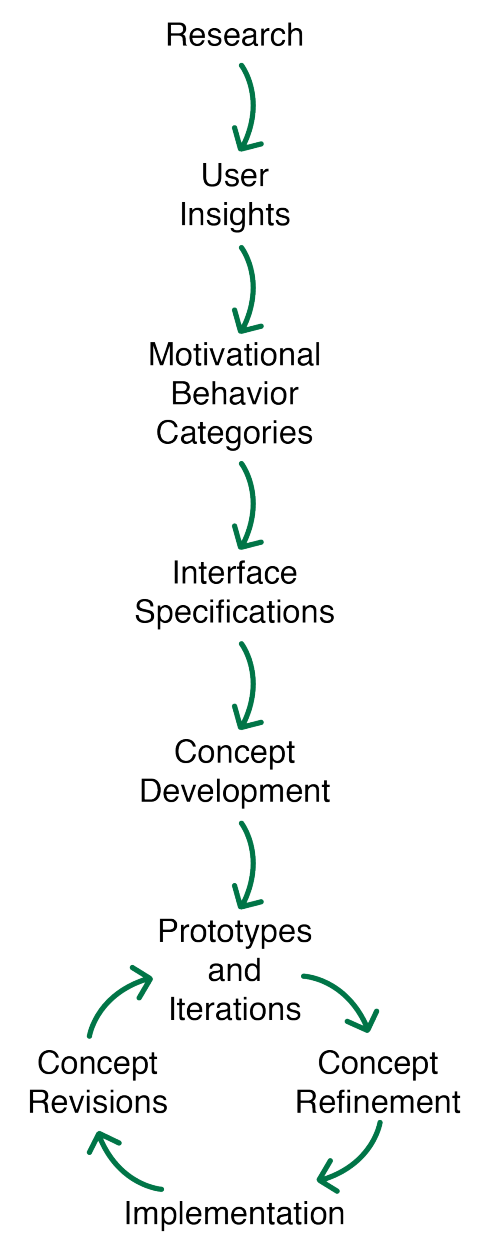

figure 1: Graphical representation of the ChangeLabs design process.

\section{ACM Classification Keywords}

H.5.2 Information Interfaces and Representation: User Interfaces; ].4 [Computer Application] Social \& Behavioral Sciences.

\section{General Terms}

Design, Human Factors, Experimentation,

Measurement, Economics.

\section{Introduction}

Over the next half-century the global demand for energy will double, which will exacerbate the already pressing crises of energy over-consumption and global climate change [8]. Our energy independence and environmental and economic sustainability depend in large part on changing how the public uses energy $[1,2]$. This is especially important in residential buildings, which accounts for twenty-two percent of the electricity consumed in the U.S. [4] and contribute significantly to health issues [11]. As a response, the United States has witnessed a proliferation of smart energy sensors and related technologies for home use. For example, PG\&E, one of the major utility companies in California, is installing SmartMeters on all its customers' homes [10], and Google.org, in partnership with The Energy Detective, has developed PowerMeter to display residential electricity data online [7].

Although providing energy information may induce minimal reductions, however, it does not significantly change energy behavior [6]. The data can be too complex or boring to understand, and alone they may not provide the incentive necessary to effect behavioral change [9]. One method of changing behavior is through interactive systems, made possible by gathering information with sensors and providing feedback frequently enough for users to maintain a continual relationship with the data. Interactive systems, displayed as interfaces on home computers or mobile devices, can impact behavior through new visualization strategies, appropriate incentive systems, and social networking. Unlike a monthly electricity bill, these interfaces inform on a daily or real-time basis and can make sensor-generated data interesting and understandable, which is crucial for behavioral change interventions $[13,15,16]$.

This case study outlines research currently in progress to determine (a) the potential effectiveness of sensorbased interactive systems on reducing residential energy consumption and (b) the relative effectiveness of interfaces based on three distinct motivational frames: cognitive, social, and affective. We will discuss these frames later in this paper.

This project is being conducted by Stanford ChangeLabs, where we are exploring mechanisms for large-scale transformations in rapid time frames. Stanford was recently awarded a highly competitive federal grant from ARPA-E to generate means of significantly reducing average residential energy use through interactive digital media, innovative data visualization, incentive systems, and community programs for energy efficient technologies. We are an interdisciplinary team of designers and engineers focused on the user experience of energy behavior interventions. This paper represents the first working model of this exploration.

\section{Ethnography and Motivation Research}

Our study began with a qualitative research phase using ethnography techniques borrowed from cultural 


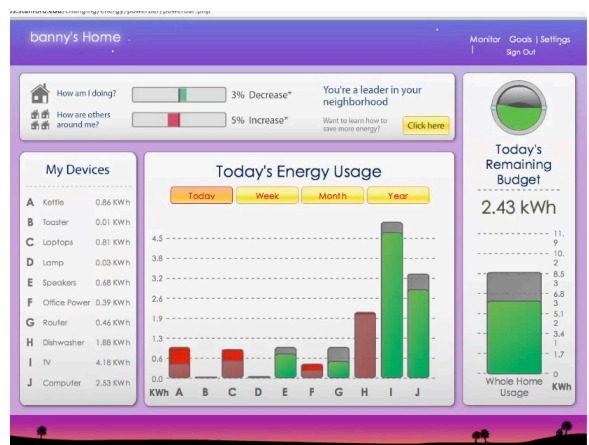

figure 2: Powerbar interface displaying realtime data in a visually appealing manner.

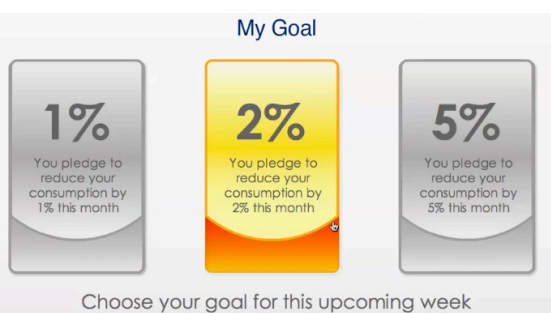

figure 3: Achievable goals for the Powerbar interface.

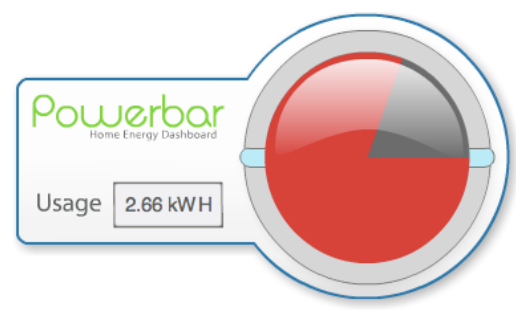

figure 4: The color and speed of Powerbar's rotating dial convey a user's rate of energy consumption at a glance. anthropology. We conducted over 40 interviews in homes and in the context of the interviewee's work places. The goal of our ethnography research was to understand the motivations underlying users' daily decisions in order to uncover mental models, mental barriers or biases, and opportunities for better energy behavior.

To gain insight into the minds of our users, in addition to interviewing typical California homeowners, we also studied the behavior of energy consumers who can be called extreme users. Extreme users-such as egregiously wasteful or extremely frugal consumersare people whose needs or motivations are more intensely felt than the typical homeowner's.

Particularly we were interested in the role that energy plays or does not play in their decisions, lifestyles, home dynamics, mental models, and mental biases, and we noted triggers that could motivate them to change their routines. Studying extreme users was an important part of our process because they help clarify opportunities and barriers in ways that frame the boundary conditions of the issue. They were sources of valuable insights that impacted our design decisions.

After generating a large body of insights from our ethnography research, we sorted the homeowners' behavioral patterns for saving energy according to the underlying motivations. We selected three of the most common and fundamental motivational driverscognitive, social, and affective-to use as distinct frames for designing interfaces aimed at changing behavior with the view of conducting research of their relative efficacy when combined with different types of users.

\section{Concept Generation}

The research phase of our project made apparent several challenges that an effective interface must address. It revealed deep confusion by the units used for energy and a lack of understanding of the sources and quantity of energy is consumed at home. An important goal of all the interfaces, therefore, must be to use intuitive ways to educate people in how to interpret energy data. Furthermore, our research suggested that users driven primarily by technical, social, or emotional affinities would opt for interfaces with different underlying logic.

After rounds of structured brainstorming that generated thirty to fifty interface concepts for each motivational category, we narrowed down to our final concepts through rapid prototyping and iterative testing. We identified the key attributes the interfaces should include and determined how to make them internally consistent. We based their visual expressions and semantic structures on principles derived for each category. After designing wire frames for the interfaces, we critiqued, iteratively tested, and visually modified them until coming to one coherent interaction. Paper prototypes and Flash-based interactive mock-ups enabled us to rapidly model these interactions. Video narratives depicting choices, predicaments, and actions helped us develop intended usage scenarios. The final interface designs then moved into the software development stage in preparation for being implemented in our field study. Although we have tested the prototypes on an ongoing basis, more iterating will be necessary. We will introduce modifications as we learn more about the nuances of the user interaction and the results of pilot tests of the functional systems with live sensor data. 


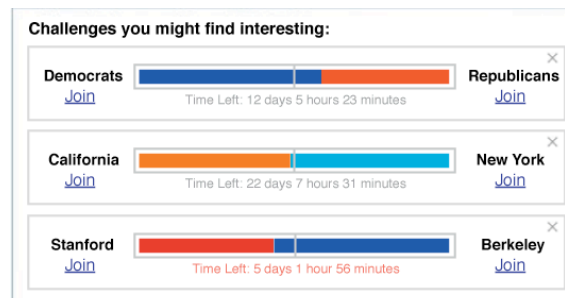

People with Google PowerMeter you might want to challenge:

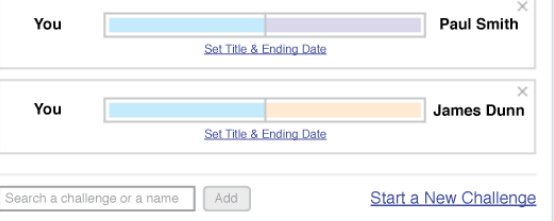

figure 5: Users can engage their social networks in multiple social competitions simultaneously with the Split Bars interface.

\section{Behavior-Changing Interface Design}

Our cognitive, social, and affective motivational frames resulted in interfaces that share technical commonalities but differ in information-framing schema. With motivationally framed interfaces the study will (a) comment on the generalized impact of interfaces in domestic energy use, (b) explore whether there is a match between type of user and success of a given category, and (c) compare the relative efficacy of the different motivational frames. Descriptions of the interfaces follow.

A) Cognitive Interface: The cognitive interface uses innovative visual displays of data and trends to motivate behavior change by encouraging interpretation and thinking in rational, pre-frontal cortical cognition [2]. Specifically, it offers real-time data, visual representations of data trends and user progress, and the ability to set energy use goals to educate users through active rather than passive feedback [3]. The interface supplements the traditional monthly paper energy bill with an interactive tool that allows a homeowner to easily understand her electricity data and challenge herself to conserve.

The interface developed to reflect the cognitive behavioral model is called Powerbar. Powerbar uses an original algorithm to set a user's energy use baseline and measure her progress in energy saving. It displays real-time data in bar graphs that express trends over weeks, months, and years [fig. 2]. Users can challenge themselves to achieve goals in decreasing energy use by $1 \%, 2 \%$, or $5 \%$ per month [fig. 3]. The Powerbar interface emphasizes easily understandable and appealing graphics and interactions. For example, one feature is a rotating dial whose frequency and color (red or green) depict whether or not the user is on track to meet her target [fig. 4]. The dial displays data in a simple way that can be interpreted at a glance. Established Behavioral Science principles such as Goal Setting, Feedback, and information Framing are utilized in this interface.

B) Social Interface: In this frame, rather than targeting a large percentage reduction in one home, the aim is to achieve wider-spread behavior change by encouraging users to involve their established social networks in collective reductions [12]. Mechanisms such as collective goals, team play, and the feeling of responsibility for the group's status come into play. The user's main motivation in this case is social currency, social engagement, and competition.

The interactive social application developed for this research project is called Split Bars. Split Bars allows users to join or create social challenges to conserve energy. The user can elect to compete individually or be part of a team and is encouraged to engage in several contests simultaneously [fig. 5]. The challenges are time-bound and can lead to rewards to increase the engagement of different social networks.

C) Affective Interface: This approach maps energy savings to some other issue, in this case microfinance, with which a user may feel emotionally connected.

The primary driver in this method is an emotional need to support a social cause that can only be contributed to in a currency of energy savings.

The interface developed according to the affective behavioral model is an application called Kidogo. The 


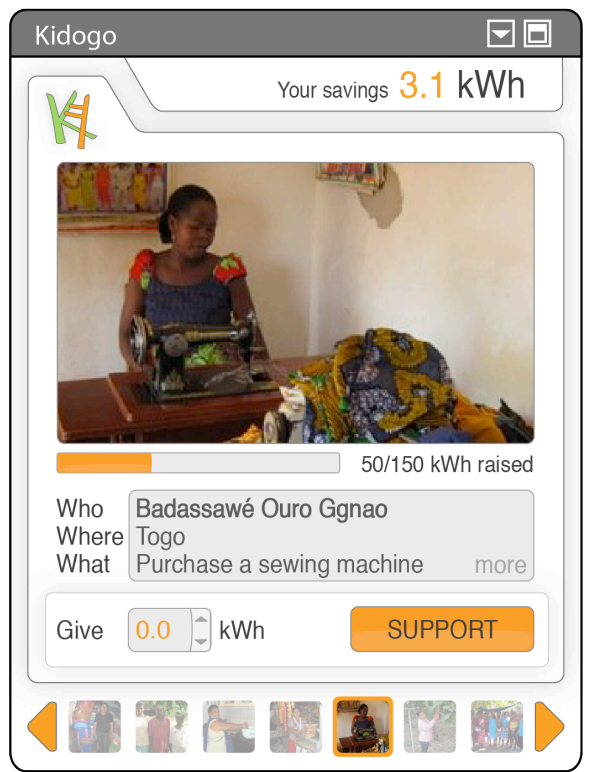

figure 6: An entrepreneurial profile in the Kidogo application. name Kidogo is Swahili for "a little bit," which reflects the idea that by saving even only a little bit of energy, users can support entrepreneurs in developing nations. Kidogo uses the original concept of nanofinance, which is a lending model that suggests that even the smallest of contributions is a useful contribution. Kidogo sets up loan challenges through the microfinance institution Kiva.org. A homeowner uses the application to donate her energy savings to any of Kidogo's entrepreneurs. Kidogo reinvests users' savings as entrepreneurs repay the loans. The affective goal is that users develop emotional connections with the entrepreneurs and are motivated to conserve more electricity in order to support them with their energy savings.

\section{Conclusion}

One of the most notable outcomes of this research is a new approach to developing interactive systems that combines the rigorous use of the Stanford Design Methodology [14] with the strategic use of insights from the behavioral sciences. This approach is bringing about a new epistemology for intervention design for large-scale changes.

Through the combination of ethnography, rapid prototyping and concept generation, and a strong theoretical framework, the process leads to creative solutions supported by effective behavioral techniques and theoretical bases. This is particularly important for the development of interventions tailored for such a complex, critical, and pervasive issue as energy.

The motivationally framed interfaces readily lend themselves to testing what variables are most effective in changing behavior. At a higher level, the concept of framing interventions with behavioral science principles can be applied to domains other than energy. We have already seen this have an impact on our industry partners, who are drawing inspiration from our approaches for their own interfaces.

We have made significant progress in understanding what influences individuals when it comes to home energy use and the design of data display systems. To date we have completed ethnographic research that provides insight into the nuances of daily energy habits, the diversity of usage scenarios, users' underlying mental models, and the barriers to change.

The interfaces provide a critical learning tool for individuals who understand little about their energy bill and how their behavior will affect it. Through smallscale testing in homes and user testing of interface prototypes, we have been able to hone the interfaces' interactions. We are preparing for scaled studies by developing the interface software and a database backend, study design, and agreements with utility companies and industry partners.

The uncertainty about our energy future is a crisis of enormous import for which the traditional interventions have been (a) higher efficiency: allowing people to do the same thing they did with less energy, (b) shifting to renewable sources: wind, solar, and bio-fuels, for example, (c) pricing signals: e.g. dynamic demand pricing. Behavior change presents a fourth approach with potentially significant impact and diffusion rates. This paper represents one of the early structured interventions for this important new approach to a challenge of critical urgency. 


\section{Acknowledgements}

We would like to thank the following people for significant contributions to the project: Marilyn Cornelius, Tom Mercer, Danya Volkov, and Brendan Wypich for ethnography research; Tom Robinson, Abby King, Eric Hekler, and Carrie Armel for advice on behavioral sciences; Purin Panichpant, Santhana Balaji, Abby Sturges, and James Thompson for their help in concept generation; Byron Reeves for his guidance; Stanford Mechanical Engineering Department for summer research funding under the SURI grant program.

\section{References}

[1] American Physical Society. Energy Future: Think Efficiency. Energy Future Report (2008), 1-109. http://www.aps.org/energyefficiencyreport/.

[2] B. Metz, O.R. Davidson, P.R. Bosch, R. Dave, L.A. Meyer. Climate Change 2007: Mitigation of Climate Change. IPCC. Cambridge University Press, New York, NY, USA, (2007), 851.

[3] Darby, S. Making it Obvious: Designing Feedback into Energy Consumption. Proc. Energy Efficiency in Household Appliances and Lighting, 2000.

[4] Department of Energy. http://www.energy.gov/.

[5] Frith, C.D., Friston, K., Liddle, P.F., Frackowiak, R. S. J. Action and the Prefrontal Cortex in Man: A Study with PET. Proceedings: Biological Sciences, The Royal Society (1991), 241-246.

[6] Froehlich, J. The Design of Eco-Feedback Technology. Proc. CHI 2010, ACM Press (2010), 1-9.

[7] Google PowerMeter.

http://www.google.com/powermeter/.

[8] Hemminger, John. New Science for a Secure and Sustainable Energy Future: A Report of a

Subcommittee to the Basic Energy Sciences Advisory

Committee. US Department of Energy (2008), 1-2.
[9] Parker, D., Hoak, D., Meier, A., Brown, R. How Much Energy Are We Using? Potential of Residential Energy Demand Feedback Devices. Proc. ACEEE. Summer Study on Energy Efficiency in Buildings, (2006), 2-11.

[10] PG\&E SmartMeter.

http://www.pge.com/smartmeter/.

[11] Pierce, J., Odom, W., Blevis, E. Energy Aware Dwelling: A Critical Survey of Interaction Design for Eco-Visualizations. Proc. OZCHI 2008, ACM Press (2008), 1-7.

[12] Schultz, P., Khazian W., and Zaleski, A. Using Normative Social Influence to Promote Conservation Among Hotel Guests. Social Influence, 3, (2008), 4-23.

[13] Socolow, R. H. The Twin Rivers Program on Energy Conservation in Housing: Highlights and Conclusions. Saving Energy in the Home: Princeton's Experiments at Twin Rivers. Cambridge, MA: Ballinger Publishing Company, (1978), 2-62.

[14] Stanford Institute of Design. http://www.design.stanford.edu/PD/.

[15] Wilson, A. \& Yost, P. Buildings and the environment: The Numbers. Environmental Building News, (2001), 10.

[16] Winett, R.A., Kagel, J. H., Battalio, R. C., Winkler, R.C. Effects of Monetary Rebates, Feedback, and Information on Residential Electricity Conservation. Journal of Applied Psychology 63 (1), (1978), 73-80. 